\title{
Luiz Simões Lopes entre administração e política: a trajetória de um dirigente
}

\section{Daniel Ouriques Caminha'}

1 Universidade do Estado de Santa Catarina / Centro de Ciências da Administração e Socioeconômicas, Programa de Pós-Graduação em Administração, Florianópolis / SC — Brasil

\begin{abstract}
A partir da utilização do método biográfico, este estudo teve por objetivo analisar a origem social, a trajetória, as estratégias de ascensão, os recursos sociais herdados ou adquiridos e os respectivos princípios de legitimação de Luiz Simões Lopes, um dos homens de confiança de Getúlio Vargas incumbido de dirigir o Departamento Administrativo do Serviço Público (Dasp) durante o período do Estado Novo. Seguindo a hipótese que afirma acerca da condição periférica da sociedade brasileira e, consequentemente, da inexistência de estruturas sociais em que o título profissional seja o principal critério de hierarquização de uma sociedade humana, propôs-se aqui explicitar e analisar os condicionantes sociais que levaram Luiz Simões Lopes à condição e ao reconhecimento enquanto elite dirigente responsável pela importação de modelos e princípios da administração científica norteamericana. Assim concluiu-se que, em função das bases de dominação pessoal já existentes, os novos recursos racional-formais importados foram redefinidos nas lutas políticas pelo controle do Estado brasileiro.
\end{abstract}

Palavras-chave: Luiz Simões Lopes; elites dirigentes; Era Vargas.

\section{Luiz Simões Lopes, entre administración y política: la trayectoria de un dirigente}

A partir del método biográfico, este estudio tiene como objetivo analizar el origen social, la trayectoria, las estrategias de ascenso, los recursos sociales heredados o adquiridos y los respectivos principios de legitimación de Luiz Simões Lopes, uno de los hombres de confianza de Getúlio Vargas en la dirección del Departamento Administrativo del Servicio Público (DASP) durante el Estado Nuevo. Por la hipótesis sobre la condición periférica de la sociedad brasileña y, consecuentemente, la inexistencia de estructuras sociales en que el título profesional sea el principal criterio de jerarquización de una sociedad humana, este estudio se propone explicitar y analizar los condicionantes que llevaron a Luiz Simões Lopes a la condición de elite dirigente responsable de la importación de modelos y principios de la administración científica estadounidense. Se concluyó que, en función de las bases de dominación personal ya existentes, los nuevos recursos racionales-formales importados se redefinieron en las luchas políticas por el control del Estado brasileño.

Palabras clave: Luiz Simões Lopes; elites dirigentes; Era Vargas.

\section{The history of Luiz Simões Lopes: a leader between administration and politics}

This study is based on a biographical methodology and aims to analyze the social origin, history, ascension strategies, and inherited or acquired social resources of Luiz Simões Lopes. The research observes the respective principles of legitimation of Luiz Simões Lopes, a man trusted by Getúlio Vargas in the direction of the Administrative Department of Public Service (Dasp) during the Brazilian period called Estado Novo (New State). Given the hypothesis of a peripheral condition of Brazilian society and, consequently, the absence of social structures in which the professional title is the main criterion of social hierarchy, this article explains the conditions that led Simões Lopes to be part of a ruling elite that imported models and principles from the North American scientific administration. The conclusion is that, due to the existing roots of personal domination in Brazil, the new rationalformal resources were established in the political struggles for Brazilian state control.

Keywords: Luiz Simões Lopes; ruling classes; Vargas Era. 


\section{INTRODUÇÃO}

A partir do estudo biográfico da trajetória de Luiz Simões Lopes, líder da reforma administrativa do Estado no primeiro governo de Getúlio Vargas, este artigo se propõe a apresentar novas contribuições ao entendimento das transformações que se deram no espaço das elites dirigentes do Brasil Republicano, no período de 1930 a 1945, em nível nacional e civil. Sua pertinência consiste em fortalecer o campo teórico aplicável ao estudo de elites em sociedades da periferia do mundo, como é a brasileira, além de contribuir para renovar as discussões sobre transformações dessas elites sob o prisma da sociologia histórica de matiz francesa.

Diante disso, busca-se sustentar dois argumentos formulados com base em pesquisas já realizadas sobre essa problemática:

a) Mesmo com a estruturação e profissionalização do Estado, cujo desdobramento foi a crescente hierarquização social com base em capital escolar, o critério legítimo de hierarquização da elite dirigente nacional no período abordado é um amálgama entre o reconhecimento do carisma pessoal e a lógica impessoal da racionalidade formal-burocrática (Coradini, 1997a, 1997b, 2003; Miceli, 2001a; Seidl, 2008, 2010); e

b) A importação e a manipulação da administração científica proveniente de instituições de ensino e governamentais norte-americanas não serviram, no período estudado, para estruturar um campo acadêmico da administração no Brasil, mas como capital reconvertido nas lutas pelo poder do Estado (Bourdieu, 1996) e dos conhecimentos que conferem sua forma e direção (Dezalay \& Garth, 2002) e, consequentemente, para se opor à "velha política" das elites oligárquicas tradicionais e proporcionar às novas elites dirigentes "cosmopolitas" um papel social ampliado, munindo-as de um sentimento missionário e heroico e autorizando-as a intervir legitimamente na construção da nação (Pécaut, 1990).

Para tanto, apresentam-se indícios empíricos ao tomar como objeto o caso da trajetória de Luiz Simões Lopes, desde seu nascimento, em 1903, até o fim do Estado Novo. Portanto, o objetivo é perquirir sua origem familiar, trajetória social e profissional, seus recursos herdados e adquiridos e os respectivos princípios de legitimação que respaldaram sua inserção em posições de direção na alta esfera estatal, especificamente o fato de ter ascendido à direção de um dos mais influentes órgãos criados sob a tutela do Estado Novo - o Departamento Administrativo do Serviço Público (Dasp) - e, mediante respaldo político de Getúlio Vargas e aliados, de ter liderado a reforma administrativa do Estado e de ter sido um dos principais mediadores da importação e do uso da administração científica nela.

A escolha por Simões Lopes se deu não apenas pela grande notoriedade que obteve ao liderar o projeto modernizador do serviço público civil, conquista certamente importante para a administração pública brasileira, mas, também, por representar uma figura típica cuja trajetória o fez incorporar disposições muitas vezes contraditórias: um inusitado amálgama entre o carisma pessoal e o que há de mais racional. Isso possibilita evidenciar com maior clareza histórico-documental a justaposição de lógicas e princípios de legitimação diferentes da dominação (Bourdieu, 2008), traço que se mostra característico das elites daquele momento da história nacional.

Para atingir o que propõe, este artigo se divide em cinco seções, incluindo esta introdução. A segunda seção trata de sistematizar seus recursos teórico-analíticos. A terceira expõe seu método e 
os procedimentos metodológicos. A quarta descreve e analisa os condicionantes sociais da trajetória de Luiz Simões Lopes. E a seção conclusiva sistematiza os achados do estudo.

\section{RECURSOS TEÓRICO-ANALÍTICOS}

A década de 1930 é considerada marco divisório na introdução de mecanismos institucionais de recrutamento no Estado brasileiro. Tal teorização partiu, principalmente, de agentes políticos que à época ocupavam posições privilegiadas no Estado. Apesar de tais feitos terem sido verbalizados por esses homens, pesquisadores das ciências sociais (Diniz, 1999; Graham, 1968; Nunes, 2003; Siegel, 1964) têm desde então apontado na direção da persistência histórica de certo amálgama que mescla lógicas pessoais e impessoais nessa esfera.

Não obstante essas contribuições, mais direcionadas a análises sobre instituições do que para demonstrar empiricamente as transformações das elites que dirigem tais instituições em períodos de mudança institucional, poucos são os estudos que buscam analisar os condicionantes que podem ter determinado as transformações e respectivas reconfigurações dos princípios de legitimação das elites dirigentes que estiveram à frente desses processos (Bordignon, 2013; Codato \& Franz, 2018; Coradini, 1997a, 1997b, 1998, 2003; Dezalay \& Garth, 2002; Garcia, 1993a, 1993b; Grill, 2015; Grynszpan, 1990; Loureiro, 1997; Martins, 1987; Miceli, 1981, 2001a; Pécaut, 1990; Petrarca, 2017; Saint-Martin, 1988; Seidl, 2008, 2010). Na busca de um referencial que possibilite analisar o que se propõe, tomou-se aquele com maior caráter sociológico e histórico, cujo recurso é antes a análise de trajetórias do que de instituições. Sua gênese ocorreu na França dos anos 1970, a partir do trabalho sociológico de Pierre Bourdieu (1982, 2004, 2011). Tal vertente tem-se mostrado heuristicamente útil para evidenciar os recursos e as estratégias determinantes na formação e recomposição de grupos dirigentes em dados contextos.

Considerando as especificidades da sociedade francesa, onde prevalece maior equivalência entre o título profissional e a posição social, alguns procedimentos têm sido usados para flexibilizar tal esquema ao estudo de elites em sociedades periféricas (Coradini, 2008; Seidl \& Grill, 2013). Como aponta Coradini (2008), sua utilização no caso brasileiro impõe uma série de problemas conceituais e metodológicos. O principal deles é que a inexistência de uma estrutura social que garanta equivalência entre títulos profissionais e a posição social "implica que as estratégias dos agentes, como consequência, estejam voltadas para a acumulação do capital simbólico personificado, como condição de garantia das demais formas de capital" (Coradini, 1997a, p. 426). Ora, entende-se por capital simbólico personificado a forma de reconhecimento fundada no renome próprio. Esse modo de valorização do capital simbólico pressupõe, segundo Sapiro (2012), antes o reconhecimento pelo carisma singular do que pelo vínculo institucional e títulos. Portanto, legitima-se na autoridade carismática junto de um público, por isso sempre associado à sua pessoa. Para ser efetivo, exige-se uma rede de relações pessoais a ser mantida e a notoriedade daí deriva de realizações que têm por base códigos pessoalizados, como a honra e o heroísmo.

Em sociedades onde as esferas não conquistaram a mesma autonomia que no caso francês, o valor social dos títulos nelas obtidos não pode ser desvinculado da posição ocupada pelo agente, a partir de outros recursos sociais. Quando prevalecem mecanismos não institucionalizados e não objetivados de dominação, menos a abordagem do capital objetivado em "campos" e mais a abordagem das relações personificadas ganham peso analítico, considerando que, no caso em pauta, esse tipo de relação é 
estruturante e não residual. Nesses termos, o conceito de capital social, desenvolvido por Bourdieu (1998, p. 67) enquanto "o conjunto dos recursos atuais ou potenciais que estão ligados à posse de uma rede durável de relações mais ou menos institucionalizadas de interconhecimento e de interreconhecimento", mostra-se aqui mais proveitoso do que no estudo do caso francês, considerando que lá o critério legítimo de recrutamento e seleção de suas elites é mais universalizado, pautado em regras objetivas e formais. Isso elucida o fato de Bourdieu (1996) ter atribuído propositalmente maior ênfase aos critérios de seleção escolar do que às vantagens advindas do capital social no acesso às elites que estudou.

A superação desses problemas também envolve a importância de considerar o caráter específico e importado das instituições do Estado brasileiro no período, que, mesmo fundadas mediante atos de reforma administrativa baseados no princípio do mérito e na suposta autonomização relativa da esfera burocrática diante do universo da política, estão inseridas em um contexto de personalização das relações sociais. Assim, cabe considerá-lo como instituição importada, cuja(s) origem e condições de surgimento não se encontram no país importador. Portanto, implica os efeitos de importação dos produtos exógenos e as consequentes modificações de seus usos em estratégias pessoais para apoiar a legitimidade de posições de elite já previamente balizadas pelo capital social (Badie, 1992; Badie \& Hermet, 1993; Dezalay \& Garth, 2002).

A partir do exposto, toma-se como elemento central de análise o conceito de trajetória social (Bourdieu, 1997) para investigar o percurso de Luiz Simões Lopes de sua origem aristocrática até a posição de elite dirigente nacional no Estado Novo. Nesse prisma, ao invés de atribuir maior peso estruturante às estratégias baseadas em capital cultural objetivado, o esquema analítico privilegiará as relações entre o acúmulo de diferentes formas de capital e adotará uma perspectiva multidimensional, no sentido de que o acesso às elites e sua reprodução é respaldado por uma composição específica de diferentes tipos de capital. Para elucidar o sentido dessas relações, adota-se, como mencionado, o princípio de que o capital social e de relações personificadas (Bourdieu, 1998) tem maior peso estruturante no contexto histórico em pauta, no sentido de que as demais formas adquirem diferentes sentidos, pesos e usos em função dele. Ainda, inclui-se no esquema os efeitos da importação dos modelos de Estado dos países centrais nas lutas políticas locais (Badie, 1992; Badie \& Hermet, 1993; Dezalay \& Garth, 2002), e, ainda, a condição de fraca autonomia dos espaços sociais nas sociedades periféricas, principalmente a grande dependência delas em relação ao poder político do Estado (Coradini, 1997a, 1997b, 1998, 2003; Loureiro, 1997; Martins, 1987; Miceli, 2001a; Pécaut, 1990; Saint-Martin, 1988; Sigal, 2012).

A apreensão dos condicionantes deve ocorrer mediante o estudo das respectivas trajetórias sociais e profissionais dos agentes envolvidos. Grynszpan (1990, pp. 74-75) menciona as vantagens desse recurso analítico para tal propósito:

O exame das trajetórias individuais nos permite avaliar estratégias e ações de atores em diferentes situações e posições sociais, seus movimentos, seus recursos, as formas como os utilizam ou procuram maximizá-los, suas redes de relações, como se estruturam, como as acionam, nelas se locomovem ou as abandonam.

É proposto por Bourdieu (1997, p. 81) que o conceito de trajetória seja utilizado para romper com aquilo que se denominou "ilusão biográfica", ou seja, os sensos comuns subjacentes às noções de 
biografia e de história de vida que se colocam como produto substantivo, permanente e autônomo da vida de um "Eu" apartado da matriz de relações sociais à qual em realidade pertence e que o condiciona. Então, a trajetória romperia com essa ilusão que é própria do gênero ficcional, ao considerar a análise de uma vida como "série das posições sucessivamente ocupadas por um mesmo agente (ou um mesmo grupo) em um espaço ele próprio em devir e submetido a incessantes transformações" (Bourdieu, 1997, p. 81).

\section{MÉTODO E SELEÇÃO DAS FONTES}

O método biográfico tem sido fecundo para a reconstituição de trajetórias associadas às elites dirigentes (Charle, 2006; Miceli, 2001b; Seidl, 2013). À luz do referencial teórico adotado, ele ganha contornos específicos que diferem daquilo que comumente se vê associado à aplicação de "métodos qualitativos" em ciências sociais, como a história oral e as histórias de vida. Essas especificidades têm sido bastante discutidas (Bourdieu, 1997; Passeron, 1990; Peneff, 1994; Pudal, 1994) e podem ser assim sintetizadas: a) considerar tanto o ponto de vista objetivista quanto subjetivista na reconstituição da trajetória, sendo um o caráter objetivo das posições sociais que condicionam a existência de um agente e outro o caráter subjetivo das tomadas de posição que permeiam as representações sobre si e para com o mundo; b) o fato do termo "biográfico" ser considerado, aqui, tanto um método de pesquisa histórica quanto o lócus das fontes de dados, significando o método adequado à reconstituição de trajetórias sociais e também as fontes histórico-biográficas encontradas cuja lógica de produção reside na consagração de determinados perfis sociais e recursos (Grijó, 2008), instrumentos dos quais os grupos dirigentes dispõem para suas estratégias de reprodução (Miceli, 2001b).

Para a reconstituição da trajetória de Luiz Simões Lopes foram utilizadas fontes históricas de natureza inteiramente apologética. Para tanto foram consultados os arquivos pessoais de Simões Lopes que estão reunidos no Centro de Pesquisa e Documentação de História Contemporânea do Brasil (CPDOC) da Fundação Getulio Vargas (FGV). Foram selecionados, por meio da consulta, verbetes do Dicionário histórico-biográfico brasileiro (DHBB), além de cartas pessoais e relatos biográficos que Simões Lopes concedeu à FGV: de um lado, os depoimentos prestados para um projeto de história oral do CPDOC/FGV, denominado "Trajetória e Desempenho das Elites Políticas Brasileiras"; de outro, o livro Luiz Simões Lopes: fragmentos de memória (Silva, 2006), editado pela mesma instituição. Apesar de atender a projetos distintos, guardam em comum o fato de serem ambos frutos de iniciativas institucionais da FGV, cujo efeito, quer consciente ou não, foi eternizar determinadas notabilidades daquele que idealizou e criou a instituição.

\section{CONDICIONANTES DA TRAJETÓRIA DE LUIZ SIMÕES LOPES (1903-1945)}

O ex-diretor da Escola Brasileira de Administração Pública e de Empresas (EBAPE) da FGV, Bianor Scelza Cavalcanti, ao prefaciar a obra memorialística de Luiz Simões Lopes (Silva, 2006), busca notabilizá-lo como um "brasileiro genuíno e vigoroso, técnico com visão política, homem público com talento empreendedor, semeador de instituições, pioneiro da [a]dministração, formador de educadores, educador de líderes, fundador, presidente e presidente de honra da FGV" (Cavalcanti, 2006, p. 15).

Além de destacar seu caráter de líder polivalente em diversas dimensões de notabilização, Cavalcanti (2006) é enfático ao mencionar que: 
Luiz Simões Lopes sempre teve também a perspectiva dos problemas nacionais e a referência do que se passava no primeiro mundo [...]. Sem perder de vista o compromisso com a identidade e o interesse nacionais, era, como mostram os textos que se oferecem ao leitor, um cidadão do mundo, homem de conviç̧ões fortes e sentido estratégico de missão (Cavalcanti, 2006, p. 16, grifo nosso).

Não apenas ressaltando seu traço cosmopolita, associado a um sentimento nacionalista e de dever para com o saneamento dos "problemas brasileiros", Cavalcanti $(2006$, p. 16) enfatiza que a vida de Simões Lopes foi marcada por paradoxos, o que não o impediu de seguir sua missão, pois lhe deram coragem para se desprender de sua origem social associada à aristocracia agrária do Rio Grande do Sul e seguir pelo caminho que estava "predestinado", no sentido de cumprir um chamamento para com a construção da nação brasileira sob bases racionais:

O Dr. Simões, como carinhosamente, respeitosamente, e, às vezes, não sem algum temor, o chamávamos, vinha de família aristocrática imperial do Sul, embora seu pai logo tenha abraçado a Revolução Republicana, contra os interesses conservadores consolidados entre os estancieiros. Filho de político e formado em agronomia, ingressou na vida pública pelas mãos do apadrinhamento, mas manteve-se sempre reticente em relação à classe política, o que não escondia dos colaboradores mais próximos, e publicamente contrário ao nepotismo (Cavalcanti, 2006, p. 16).

Eis uma amostra de como se deu o investimento institucional visando à sua consagração. Entremeado por notabilidades à primeira vista contraditórias, esse homem-camaleão foi eternizado exatamente pela ênfase nos traços que compõem sua disposição: simultaneamente cosmopolita e nacionalista; ao mesmo tempo, predestinado como um profeta e racional como um sacerdote. Inusitada mistura entre o racional e o transcendente que muito pode dizer sobre as transformações que as elites políticas vivenciaram naquele momento.

\subsection{A origem familiar}

Nascido em 2 de junho de 1903, em Pelotas-RS, Luiz Simões Lopes proveio de uma família tradicional da aristocracia estancieira gaúcha, bem inserida na política local e nacional. Seu avô, João Simões Lopes Filho, foi um barão que ascendeu ao título de Visconde da Graça, também estancieiro e presidente da Província do Rio Grande do Sul, em 1871. Já o pai de Luiz, Ildefonso Simões Lopes, foi: deputado federal entre 1906 e 1908 e entre 1913 e 1919; Ministro da Agricultura entre 1919 e 1922, durante o governo de Epitácio Pessoa; e deputado federal de 1922 até 1930.

A partir de verbete incluído no DHBB (Moreira, 2001), convém situar a posição de Ildefonso, o pai, para lançar luz sobre as estratégias familiares que condicionaram a trajetória de Luiz. Também nascido em Pelotas, em 19 de novembro de 1866, inicialmente Ildefonso preferiu exercer a profissão de engenheiro, cujo diploma obteve em 1890, trabalhando durante alguns anos na construção de estradas de ferro em Minas Gerais, em São Paulo e no Rio de Janeiro. Quando regressou a Pelotas, em 1895, dedicou-se aos negócios familiares, dirigindo até 1905 a Hidráulica Pelotense, de propriedade do visconde da Graça. A reconversão de Ildefonso à política partidária e eleitoral só ocorreu posteriormente, quando se filiou ao Partido Republicano Rio-Grandense (PRR). 
A ascensão de Ildefonso ao poder político local e, tempos depois, à esfera nacional parece manter certa homologia com a elite política rio-grandense nascida no final do século XIX, cuja carreira se iniciou no PRR à época de Borges de Medeiros como presidente provincial. Segundo Grijó (1998), ela tinha origem social muito semelhante à de Ildefonso, pois seus integrantes também eram de famílias aristocráticas, salvo a diferença na trajetória escolar, predominantemente associados ao direito. $\mathrm{Na}$ percepção de Luiz (Simões Lopes, 1986), esse grupo, mesmo já privilegiado, chegou ao poder político porque era o natural, tratava-se do grupo mais culto. Todos guardavam relação com certo ideário positivista: tomando posições por uma organização elitista da sociedade, eram avessos ao liberalismo político, questionavam o individualismo e defendiam o caráter científico do poder e a primazia do bem comum sobre o particular (Pécaut, 1990).

Em síntese, na condição privilegiada que tinha a família de Luiz, e pela valorização cada vez maior do capital escolar como recurso para ingressar na política, convertia seu cabedal econômico e social na escolarização dos filhos. Coradini (1997a) menciona que, pelo peso que tinha o capital social e as relações personificadas nas estratégias de ascensão das elites, o ingresso e o investimento escolar eram muito dependentes dessas relações de clientela, que tanto garantiam o acesso às escolas de maior prestígio quanto redefiniam o significado do título escolar enquanto garantia de inserção na política.

\subsection{0 investimento escolar}

Mesmo tendo aprendido as primeiras letras em um pequeno colégio pelotense, foi somente com a brusca mudança para o Rio de Janeiro com seu pai (Simões Lopes, 2006b), quando ele se elegeu novamente deputado federal, em 1913, que Luiz iniciou sua trajetória propriamente escolar no Colégio Aldridge e no Liceu Francês. Eram instituições de excelência. Como aponta o próprio Luiz, "além dos bons cursos, nos orientavam nos bons modelos da moral e da religião católica, embora fossem protestantes, do esporte, da dignidade pessoal, da coragem e da lealdade" (Simões Lopes, 2006a, p. 47).

Concluída sua fase escolar inicial, Simões Lopes (2006a, p. 48) afirma ter-se sentido "atraído pela carreira agronômica, talvez pelas lembranças inesquecíveis da minha meninice na Estância da Graça”. Não demonstrando arrependimento, julgou a escolha muito útil, mesmo com a vida o levando "para caminhos tão diferentes" (Simões Lopes, 2006a, p. 48). Dedicando-se ao estudo, mudou-se sozinho para a cidade de Piracicaba (São Paulo), em 1920, com o objetivo de matricular-se em engenharia agronômica na Escola Agrícola Luiz de Queiroz.

De seu convívio com alunos, professores e a comunidade em geral de Piracicaba, Simões Lopes (2006a, p. 51) guardou em sua vida muita saudade, isso porque "conhecia a todos, desde o prefeito até o engraxate, tinha ótimas relações com as famílias piracicabanas, e era numerosa a colônia gaúcha”. Da vida nas agremiações estudantis, rememora que foi o principal agente de revitalização do Centro Agrícola Luiz de Queiroz, entidade que agremiava professores e alunos, da qual foi presidente. Em suas memórias, menciona: "em virtude da posição que assumi, tornei-me um líder estudantil, sempre chamado a intervir nos conflitos dos estudantes com a população" (Simões Lopes, 2006a, p. 51, grifo nosso).

Entretanto, os tempos de paz terminaram quando Luiz se envolveu em um incidente com um soldado da Política Militar, que resultou em ferimentos e na expulsão da Escola Agrícola. Após 
sua recuperação, viu-se obrigado a se transferir para Belo Horizonte, em 1924, lá concluindo o último ano do curso de engenharia agronômica na Escola Mineira de Agronomia e Veterinária. Após concluir o curso, em 1924 obteve o título de engenheiro agrônomo. Não apenas pelo peso do título profissional, mas também, e principalmente, por um conjunto de relações pessoais baseadas nos vínculos de seu pai com a elite política federal, conseguiu ingressar no serviço público civil, obtendo indicação por parte do então Ministro da Agricultura Miguel Calmon para preencher uma função em seu ministério.

\subsection{0 ingresso no serviço público}

Apesar de ter entrado no Ministério da Agricultura por força do "pistolão", assim que assumiu suas funções, Luiz afirmou ter ficado profundamente chocado com a forma como a maioria dos funcionários públicos ingressavam, "sem prestar concurso, sem nenhuma prova de capacidade técnica nem de idoneidade moral" (Simões Lopes, 2006a, p. 54, grifo nosso). Como ainda não havia mecanismos de carreira pautados em regras formais de acesso e progressão no serviço público civil, ao ingressar por indicação política, Luiz teve a possibilidade de escolher um entre os diversos cargos que lhe estavam disponíveis. Recorrendo ao "bom senso" (Simões Lopes, 2006a, p. 54), escolheu o cargo mais baixo entre os ofertados, em uma estação experimental de plantas forrageiras. Tempos depois, o Ministro Calmon lhe ofereceu um cargo em seu gabinete ministerial, o qual aceitou por estar descontente com o diretor da sua divisão. Lá encontrou "excelentes funcionários, como Paulo Vidal, que iria depois trabalhar comigo no Dasp, Arno Konder, depois embaixador, e outros. Muito aprendi, fiz grande relacionamento com políticos e autoridades e na sociedade carioca" (Simões Lopes, 2006a, p. 55, grifo nosso).

Se até 1929 Luiz foi um funcionário de gabinete no Ministro da Agricultura, atuando em questões técnicas especificamente ambientais, a partir da campanha iniciada em 1929 pela Aliança Liberal (AL), reconverteu-se, cada vez mais, ao envolvimento "com o problema político" da nação (Simões Lopes, 2003, p. 2). As relações políticas de Luiz com a AL se iniciaram pelo fato de seu pai ter sido o vice-presidente do grupo. Por considerar que seu pai era o "verdadeiro presidente", colocava-se como uma espécie de secretário dele. A campanha aliancista para eleger Getúlio Vargas atravessou dificuldades, pois os demais estados, exceto Rio Grande do Sul, Minas Gerais e Paraíba, apoiavam a candidatura do paulista Júlio Prestes. O desdobramento, como se sabe, foi a Revolução de 1930 após a vitória de Prestes, levando a aliança de Vargas a instaurar o Governo Provisório.

O início da proximidade de Luiz com Vargas não se deu apenas por sua participação ativa na Revolução de 1930, mas pelas relações pessoais já existentes entre as famílias Simões Lopes e Vargas, que se frequentavam desde o início da década de 1920, quando Getúlio e Ildefonso faziam parte da bancada gaúcha na Câmara dos Deputados. O capital social familiar acumulado e herdado por Luiz, a partir dessas relações entre ambas as famílias, teria forte peso na decisão de Vargas de chamá-lo para ocupar uma posição privilegiada em seu gabinete presidencial.

Paralelo a isso, os acontecimentos que levaram Vargas ao poder representaram bem o momento em que Luiz passou a ampliar e diversificar seu espectro de interesses: para além das questões eminentemente técnicas com que lidava corriqueiramente em sua função pública, adotou novas posições relativas aos desafios e problemas políticos nacionais, principalmente pondo em destaque a necessidade de reformular, sob bases científicas, o serviço público no Brasil. 


\subsection{0 acesso à elite política de Vargas}

A participação de Luiz na Revolução de 1930 foi episódica e ficou restrita ao Rio Grande do Sul. Não obteve sucesso em organizar uma força local para se juntar às tropas revolucionárias. Como ainda era funcionário público efetivo no Rio de Janeiro, Luiz se viu obrigado a voltar à capital. Considerando que Luiz e Vargas já se conheciam, por conta das relações familiares, assim que retornou ao Rio, Vargas, já ocupando o posto de chefe do Governo Provisório, chamou-o pessoalmente para lhe estender um convite para atuar como seu oficial de gabinete.

Inicialmente, quando assumiu o Governo Provisório, Vargas havia decidido trazer para assessorálo dois homens de confiança que trabalhavam com ele no governo do Rio Grande do Sul. Estes, no entanto, pouco conheciam o Rio de Janeiro e não tinham o trunfo dos bons relacionamentos com políticos e autoridades da sociedade carioca, adquirido por Luiz nos tempos de gabinete do Ministro da Agricultura e de assessoramento de seu pai na AL. Como Vargas já tinha relações com Luiz, e por saber que ele já havia trabalhado em gabinete, acreditava que poderia colocar ordem na bagunça que havia se instaurado em seu gabinete e organizar a agenda presidencial. Assim, Luiz permaneceu nessa posição até 1936, quando o próprio Vargas o convidou novamente para ser Presidente da Comissão de Reajustamento dos Funcionários Civis, uma das grandes iniciativas da reforma administrativa.

Pela imersão no gabinete de Vargas, as impressões que Luiz germinava desde a década de 1920 adquiriram maior robustez em seu pensamento a partir de 1930, isto é, os pendores pela organização racional do funcionalismo e o grande entusiasmo pela Revolução de 1930, foram suficientes para que ele conquistasse a confiança do novo presidente, tornando-se o principal nome à frente da reforma administrativa que seu governo pretendia levar a cabo.

A propósito da organização racional, percebe-se nas tomadas de posição de Luiz que ela é o elo que bem une a "competência para dirigir" do novo governo com as ideias de "elevada integridade moral" e "razão", marcas do já mencionado ideário positivista rio-grandense que adquiriu pelo contato precoce que teve com a elite política de seu estado natal, agora consolidada como elite nacional:

[...] parecia o instrumento capaz de transformar o Brasil no país dos nossos sonhos, próspero, livre, feliz, dirigido por um governo altamente competente, honesto e bem-intencionado, governo inspirado na moral e na razão, como diriam os positivistas (Simões Lopes, 2006d, p. 77, grifo nosso).

\subsection{Liderança diante a criação do Dasp}

Já ocupando o posto de oficial de gabinete de Getúlio Vargas, Luiz passou a ter, a partir de 1935, participação ativa na reforma do serviço público civil, deflagrada pelo Governo Vargas com a criação da Comissão Mista de Reforma Econômico-Financeira. No entanto, o relatório final dessa comissão não foi aceito pelo Poder Legislativo. Uma nova tentativa ocorreu em 1936, quando Vargas criou a Comissão de Reajustamento convidando Luiz para presidi-la. Um novo projeto foi mandado ao Legislativo, que sugeriu algumas emendas, mas, por força da maioria que o governo tinha na Câmara, foram rejeitadas. Assim, a "lei passou incólume aos assaltos dos que desejavam alterá-la, para servir a interesses pessoais, e tomou o número 284, de 1936” (Simões Lopes, 2006c, p. 91). 
Sobre a lei, Simões Lopes (2006c) tomou a seguinte posição:

Além de dar organicidade ao sistema de pessoal, trazia em seu bojo uma série de princípios indispensáveis a uma administração moderna, não casuística, regida por normas gerais, honestas e rígidas que orientariam dali para a frente o serviço civil brasileiro. Era um sistema monolítico, feito com absoluta lisura, que dispensava tratamento equânime a todos (Simões Lopes, 2006c, p. 91).

Então, Luiz foi nomeado por Vargas para presidir o Conselho Federal do Serviço Público Civil (CFSPC), órgão criado pela Lei n. 284 (1936) para aplicar as novas normas, até sua extinção, no final de 1937, quando se instaurou o Estado Novo, que fechou o Poder Legislativo e outorgou a Constituição dos Estados Unidos do Brasil (Constituição, 1937), tornando a eficiência no serviço público um princípio constitucional, "como um dever do Estado para com o país, para com os cidadãos, para com o povo" (Simões Lopes, 2006c, p. 92). Do mesmo modo, a Constituição (1937) criou um órgão substituto ao CFSPC, agora diretamente subordinado à Presidência da República. Este novo órgão, o Dasp, para o qual Luiz foi nomeado por Vargas em agosto de 1938, para ser o presidente, e por lá permaneceu até o fim do regime, em 1945, era dotado de maior poder regulador e ingerência do que seu antecessor.

Em suas tomadas de posição sobre esse momento, quando de sua inserção no alto escalão da burocracia pública, via Dasp, Luiz Simões Lopes passou, cada vez mais, a destacar a importância que atribuía ao serviço público. Em uma carta encontrada em seu arquivo pessoal no CPDOC/FGV, sem data ou mesmo destinatário, nota-se o amadurecimento de seu ideário já nascente nas posições que vinha tomando desde seu engajamento na Revolução de 1930: colocar-se a serviço de causas nacionais e do progresso do país pela via da modernização do serviço público:

Meu amor pelo serviço público, pelas causas nacionais, não tinha limites. Qualquer sacrifício de mim exigido seria atendido incontinente. Eu me achava possuído de um espírito de missão e a mocidade me dava ânimo e forças para enfrentar todas as dificuldades. Era uma luta desigual e sem quartel. Não tinha descanso e não raro era o dia em que me via acuado, atacado, vilipendiado, por defender o que eu julgava ser[em] os altos interesses do Estado. Sonhava criar um grande serviço público, capaz, idôneo e respeitado, como o mais poderoso instrumento de progresso do Brasil (Simões Lopes, n.d., grifo nosso).

A ampla modernização por Luiz conduzida ao presidir o Dasp foi pautada, principalmente, pela organização de mecanismos formais de ingresso e progressão de carreiras e pelos princípios de organização racional do trabalho. Suas raízes doutrinárias, como aponta Siegel (1964), referem-se em especial à administração científica norte-americana, fazendo de Luiz um notório homem cosmopolita, antenado com o que havia de mais moderno na administração dos países centrais.

Não faltaram referências à literatura e à prática administrativas norte-americanas, como o conceito de planning, organizing, staffing, directing, coordinating, reporting, and budgeting (POSDCORB), de Luther Gulick, as concepções defendidas por William Willoughby acerca do papel dos departamentos de administração geral enquanto suporte ao Poder Executivo e da distinção entre meios (administração) e fins (política) da ação governamental, além de referências ao próprio modelo de funcionamento posto em prática pelo Civil Service Commission norte-americano. No entanto, o Dasp de Luiz não abdicou de adaptar tudo isso ao sabor da "experiência" brasileira (Wahrlich, 2001, p. 1828). Em outros 
termos, operou a adaptação de ideias provenientes de democracias liberais consolidadas para um contexto de autoritarismo governamental, dando ao departamento um poder ampliado para fazer valer o objetivo político do regime de opor-se à irracionalidade dos velhos políticos oligarcas, sempre agindo em nome da ciência e da organização da nação sob bases racionais (Pécaut, 1990).

Mais especificamente, a atuação de Luiz no Dasp gerou uma série de dispositivos modernizantes. Entre eles, cabe destacar a gestão do material, com a criação de um sistema unificado e passando a intervir, a partir de 1939, nas obras e prédios públicos ao controlar as construções e reformas e estabelecer normas para orçamentos, projetos e contratos de obras. Também houve avanços na organização do trabalho, onde o Dasp centralizou todas as atividades de pesquisa e projeto sobre métodos de trabalho, criando uma subdivisão somente para tanto.

Ainda com o objetivo de centralizar ao máximo as atividades, institucionalizou-se o recrutamento de servidores públicos por critérios universais meritocráticos, via concursos, e a responsabilidade de realizá-los. Paralela aos concursos, criou-se a carreira de técnico em administração, a ser preenchida pelo pessoal aprovado nos exames. Não apenas o recrutamento, mas o progresso na carreira era uma preocupação de Luiz. Para tanto, institucionalizou no Dasp a ideia de qualificação profissional e aperfeiçoamento. Como informa Simões Lopes (2003), duas frentes foram criadas: a) os cursos próprios de formação e aperfeiçoamento de funcionários, a partir do Decreto-Lei n. 2.804 (1940); e b) o envio deles para capacitação em cursos e estágios técnicos no exterior, a partir do DecretoLei n. 776 (1938), sendo a principal instituição acolhedora a School of Public Affairs da American University. Como bem destaca Wahrlich (1983), os cursos do Dasp e o envio ao exterior foram um marco na formação do administrador profissional brasileiro, considerando seu pioneirismo no país.

Ainda, convém mencionar outra ação pioneira de Luiz à frente do Dasp. Trata-se da criação da Revista do Serviço Público (RSP), que contribuiu para a construção de uma nova mentalidade técnica e científica no serviço público, difundindo ideias sobre a administração e a organização científicas no Brasil e servindo muito bem para que o Dasp fizesse uma alusão positiva ao regime, ao propagandear os benefícios da modernização em curso.

É possível notar que Luiz, durante o regime, atribuía a si o status de elite dirigente, pois se via pertencente ao grupo dos modernos e eficientes opondo-se à "velharia administrativa" que sobrevivia nos níveis locais, fruto da "atrasada" política oligárquica dos estados. Segundo Simões Lopes (2003, p. 41), "nos estados e municípios não compreendiam a necessidade e até não gostavam, porque preferiam ter liberdade total, como faziam antes, de nomear quem eles quisessem, sem concurso, sem nada, nomear os parentes". As demonstrações de que ele se via como elite capaz, portador de uma missão e defensor do interesse amplo de construir a nação (Pécaut, 1990), são muitas e expressam-se em outras tomadas de posição de Luiz, como a que segue:

Motivados por um imenso amor à causa pública, eram arautos de uma ideia nova. Traziam com eles, onde andavam, uma mensagem de confiança, de melhoria cada vez maior dos métodos de trabalho, da orientação governamental. Porque éramos todos, então, paladinos de uma causa e não aceitávamos nunca as nossas vitórias como finais, mas sempre achávamos que ainda devíamos muito, tínhamos o dever de dar, cada vez mais, novas contribuições à administração pública de nosso país. Assim, vivemos aqueles longos anos de luta, de sofrimento, gratificados pela convicção íntima de que estávamos fazendo algo muito importante para a vida do país (Simões Lopes, 1986, p. 51, grifo nosso). 
Do mesmo modo, grande importância era atribuída ao papel do Estado nos "países pobres". A percepção de Simões Lopes (1986) era tanto mais direcionada à necessidade de um Estado forte em um país em vias de desenvolver-se, modernizar-se, como o Brasil, que acreditava que nos países ricos a iniciativa privada era capaz de levar um país adiante e promover o desenvolvimento por meio do trabalho, da maior produtividade, melhores salários e melhor padrão de vida. No caso dos países pobres, nomenclatura por ele próprio adotada, o Estado tinha uma imensa tarefa a realizar:

No governo dos países subdesenvolvidos, e mais pobres, deveria estar a elite intelectual da nação, os homens mais preparados, mais inteligentes, mais patriotas, mais dedicados, que tivessem uma espécie de sentimento de compromisso para com o serviço público, que se sentissem responsáveis perante o povo, que quisessem fazer do seu país um país modelar (Simões Lopes, 1986, grifo nosso).

A partir da década de 1940, Luiz passou a defender a urgente necessidade de criar uma instituição específica para "cuidar dos problemas do país". Entretanto, como tinha consciência de que não era possível cuidar de todos, foram escolhidas as "ciências sociais" como principal meio de solução dos males, com ênfase na administração e na economia. Esses dois campos concentravam os principais problemas já enfrentados pelo Dasp. Foi assim que, em 1944, ele participou diretamente da criação da FGV: "Dessa forma criei no Brasil a coisa mais moderna que havia, tão moderna quanto eles tinham nos Estados Unidos" (Simões Lopes, 2003, p. 54). Ao final do regime, com a queda de Vargas, Luiz decidiu deixar a presidência do Dasp e passou a se dedicar à direção da FGV, tornando-se seu primeiro presidente.

\section{CONCLUSÕES}

À luz das evidências expostas, depreende-se que Luiz Simões Lopes teve uma origem social associada à aristocracia estancieira do Rio Grande do Sul. No entanto, o que suas memórias mostraram foram tentativas de negá-la, seja ao afirmar que nunca teve "vocação para a política" ou referindo-se à estância familiar como apenas um "refúgio". Desde cedo, manifestou vocação para ser "administrador". Contudo, apesar das referências à ciência administrativa - neutra, imparcial e apolítica -, Luiz também foi um dos grandes intermediadores políticos e culturais entre 1930 e 1945. Mesmo que sua trajetória tenha sido marcada por posições cujo fundamento de legitimação tenha consistido na posse de conhecimento científico-racional em oposição à "velha política" dos tradicionais à qual esteve umbilicalmente ligado, as bases de suas tomadas de posição permaneceram fundadas em relações personificadas, viabilizadas pelo capital social herdado e adquirido durante a trajetória. Mesmo que tenha tentado negá-las, tais disposições, por assim dizer "tradicionais", aparecem em comunhão com o que trouxe de mais moderno do Ocidente.

Isso se clarifica a partir das evidências expostas. Quando os primeiros reformistas da administração pública começaram a se reunir em torno da Comissão de Reajustamento e do CFSPC, foi Luiz o homem de confiança que intermediou as escolhas políticas dos reformistas junto a Vargas e, consecutivamente, também foi ele que intermediou as escolhas para os postos de direção do Dasp, justificando suas escolhas mediante um amálgama entre o conhecimento técnico, a confiança e a elevada moral dos homens escolhidos. Para tanto, não bastava ser um perito especialista, um exímio administrador no 
sentido técnico, era necessário, ainda, ser um homem de elevada envergadura moral e afinado com a "missão" de "construir a nação" (Pécaut, 1990).

Como já mencionado, os recursos teóricos ajudam a pensar essa questão. Em uma sociedade periférica, onde mecanismos impessoais de dominação não se encontram suficientemente estruturados, são recorrentes os investimentos em capital simbólico personificado (Coradini, 1997a), sempre associados às relações pessoais que os tornam possíveis. Nesses termos, o que se depreende com a trajetória de Luiz é que não apenas as sucessivas posições de elite foram ocupadas pelo acionamento de relações personificadas, mas que, também e paralelamente, buscou-se legitimar essa condição de notoriedade por meio da definição de seu papel de "herói modernizador" e, respectivamente, da "missão" a que se viu destinado, de "construir a nação", tendo ele exclusivamente um "papel ampliado" na sociedade. É desse modo que, nas memórias acerca de sua vida, Luiz define sua condição de elite mediante um amálgama de características impessoais e pessoais.

Tal explicação poderia muito bem ser tratada a partir da transformação do universo das gramáticas políticas (Nunes, 2003), que enfoca o nível das instituições estatais. Nessa ótica, o que se observa é que, nos 15 anos do primeiro governo de Vargas, 3 novas gramáticas (corporativismo, insulamento burocrático e universalismo de procedimentos) foram mobilizadas em um universo onde já prevalecia a gramática do clientelismo. Essa nova composição teria condicionado o acesso das oligarquias estaduais remanescentes da República Velha à Nova República. Porém, o que este estudo se propôs a enfocar não repousa na esfera das transformações institucionais, mas nas transformações das elites dirigentes nacionais do momento, a partir da análise de uma trajetória específica.

O caso de Luiz é, como se viu, particularmente ilustrativo, pois traz à tona uma contradição marcante de sua época: o fato de que a modernização estatal pós-1930 foi obra de uma elite aristocrático-agrária de estados periféricos na federação (no caso, o Rio Grande do Sul) se opondo ao predomínio paulista de até então (Garcia, 1993b). Questiona-se por que um homem cuja base de poder político residiu justamente em critérios pessoais investiria tanto empenho em trazer ao seu cenário bases de legitimação dos grupos dirigentes, que, se seguidas ao pé da letra, universalizariam $\mathrm{o}$ acesso às posições mais prestigiosas e minariam as bases pessoais prévias que lhe asseguravam o acesso restritivo.

Nesse caso, não se pode pensar que esquemas dualizados poderiam solucionar o problema (Garcia, 1993b). Ao se colocar de um lado o universo tradicional e do outro aquele da modernização do Estado, evita-se ver que as estratégias dessas novas elites da política nacional, caso de Luiz, jogavam com a diversificação estratégica e o acionamento de diferentes formas de capital, habilmente resguardando os postos mais rentáveis da expansão da concorrência em consequência da chegada dos "princípios universais" de recrutamento e seleção. Talvez a conclusão mais geral que possa se extrapolar disso é a de que certas famílias tradicionais de estados politicamente periféricos passaram a diversificar suas estratégias para se afirmarem no poder político nacional, vinculando às trajetórias de seus descendentes a transferência dos recursos associados ao capital econômico e social com investimentos em capital cultural.

Ao invés de dualismo, pensa-se no amálgama daí resultante, contradição não resolvida pela história, onde um caso de herdeiro da aristocracia agrária rio-grandense conseguiu se lançar à posição dirigente em nível nacional no papel de "herói modernizador", portador de uma "missão" de construção nacional, sabendo lidar habilmente com as bases pessoais que sempre condicionaram suas estratégias de ascensão à posição de elite nacional e com um papel de mediador diante dos 
princípios universais que importou; entre eles, destaca-se o papel de intermediador na importação da administração científica norte-americana pelo Estado brasileiro. Desse amálgama resulta o fato de que o acesso ao papel de mediador na importação desses princípios universais não era de todo universal, mas fechado em torno de uma elite cosmopolita (Dezalay \& Garth, 2002) portadora do sentido de missão e de heroísmo, ou seja, os portadores de um traço distintivo pessoal que só adquire respaldo se sustentado por uma base de relações personificadas.

Daí se pode depreender, finalmente, que são as redefinições de ciência e técnica que se encontram na base de suas tomadas de posição política, bastante afinadas com os interesses mais amplos do regime estadonovista de defender uma "política objetiva e administrativa" (Pécaut, 1990, p. 56), redefinições possíveis apenas pela condição de acúmulo prévio de capital simbólico pessoal. Em outros termos, em nome de universais e princípios gerais, apenas os portadores singulares do sentido transcendental de missão e heroísmo, ambos ligados ao carisma do portador, caso de Luiz, puderam conduzir a nação caótica e desorganizada, uma massa amorfa de átomos sem rumo definido, ao encontro de si. 


\section{REFERÊNCIAS}

Badie, B. (1992). L'État importé : l'occidentalisation de l'ordre politique. Paris, France: Fayard.

Badie, B., \& Hermet, G. (1993). Política comparada. México, DF: Fondo de Cultura Económica.

Bordignon, R. R. (2013). Origens sociais, ascensão "profissional" e concepções de ciências sociais: Florestan Fernandes e Fernando Henrique Cardoso. TOMO, 16(22), 181-220.

Bourdieu, P. (1982). Leçon sur la leçon. Paris, France: Minuit.

Bourdieu, P. (1996). The state nobility: elite schools in the field of power. Palo Alto, CA: Stanford University Press.

Bourdieu, P. (1997). Razões práticas: sobre a teoria da ação. Campinas, SP: Papirus.

Bourdieu, P. (1998). O capital social: notas provisórias. In M. A. Nogueira, \& A. Catani (Orgs.), Escritos de educação (pp. 65-69). Petrópolis, RJ: Vozes.

Bourdieu, P. (2004). Espaço social e poder simbólico. In Autor, Coisas ditas (pp. 149-168). São Paulo, SP: Brasiliense.

Bourdieu, P. (2008). Modos de dominação. In Autor, A produção da crença: contribuição para uma economia dos bens simbólicos (3a ed., pp. 191-219). Porto Alegre, RS: Zouk.

Bourdieu, P. (2011). O senso prático (2a ed.). Petrópolis, RJ: Vozes.

Cavalcanti, B. S. (2006). Prefácio. In S. B. Silva (Org.), Luiz Simões Lopes: fragmentos de memória (pp. 15-21). Rio de Janeiro, RJ: Ed. FGV.

Charle, C. (2006). A prosopografia ou biografia coletiva: balanço e perspectivas. In F. M. Heinz (Org.), Por outra história das elites (pp. 41-53). Rio de Janeiro, RJ: Ed. FGV.

Codato, A. N., \& Franz, P. (2018). Ministros-técnicos e ministros-políticos nos governos do PSDB e do PT. Revista de Administração Pública, 52(5), 776-796.

Constituição dos Estados Unidos do Brasil, de 10 de novembro de 1937. (1937). Rio de Janeiro, DF.

Coradini, O. L. (1997a). Grandes famílias e elite "profissional" na medicina no Brasil. História, Ciências, Saúde: Manguinhos, 3(3), 425-466.
Coradini, O. L. (1997b). Origens sociais e princípios de hierarquização escolar: a formação de "intelectuais à brasileira”. Cadernos de Ciência Política, 2(6), 1-55.

Coradini, O. L. (1998). Panteões, iconoclastas e as ciências sociais. In L. O. Félix, \& C. P. Elmir (Orgs.), Mitos e heróis: construção de imaginários (pp. 209235). Porto Alegre, RS: Ed. UFRGS.

Coradini, O. L. (2003). As missões da "cultura" e da "política": confrontos e reconversões de elites culturais e políticas no Rio Grande do Sul (19201960). Estudos Históricos, 2(32), 125-144.

Coradini, O. L. (2008). As elites como objeto de estudos. In Autor (Org.), Estudos sobre grupos dirigentes no Rio Grande do Sul: algumas contribuições recentes (pp. 7-18). Porto Alegre, RS: Ed. UFRGS.

Decreto-Lei n. 776, de 7 de outubro de 1938. (1938). Dispõe sobre especialização e aperfeiçoamento de funcionários públicos civis federais no estrangeiro e dá outras providências. Rio de Janeiro, DF.

Decreto-Lei n. 2.804, de 21 de novembro de 1940. (1940). Dispõe sobre a organização de Cursos de Administração e dá outras providências. Rio de Janeiro, DF.

Dezalay, Y., \& Garth, B. (2002). The internationalization of palace wars: lawyers, economists and the contest to transform Latin America States. Chicago, IL: University of Chicago Press.

Diniz, E. (1999). Engenharia institucional e políticas públicas: dos conselhos técnicos às câmaras setoriais. In D. C. Pandolfi (Org.), Repensando o Estado Novo (pp. 21-38). Rio de Janeiro, RJ: Ed. FGV.

Garcia, A., Jr. (1993a). Les intellectuels et la conscience nationale au Brésil. Actes de la Recherche en Sciences Sociales, 18(98), 20-33.

Garcia, A., Jr. (1993b). Reconversion des élites agraires: du pouvoir local au pouvoir national. Études Rurales, 32(131-132), 89-106.

Graham, L. S. (1968). Civil service reform in Brazil: principles versus practice. Austin, TX: University of Texas Press.

Grijó, L. A. (1998). Origens sociais, estratégias de ascensão e recursos dos componentes da chamada "geração de 1907" (Dissertação de Mestrado). Universidade Federal do Rio Grande do Sul, Porto Alegre, RS. 
Grijó, L. A. (2008). Biografia, para quê? In O. L. Coradini (Org.), Estudos de grupos dirigentes no Rio Grande do Sul: contribuições recentes (pp. 85-102). Porto Alegre, RS: Ed. UFRGS.

Grill, I. G. (2015). As múltiplas notabilidades de Afonso Arinos: biografias, memórias e a condição de elite no Brasil do século XX. Revista de Sociologia e Política, 23(54), 21-42.

Grynszpan, M. (1990). Os idiomas da patronagem: um estudo da trajetória de Tenório Cavalcanti. Revista Brasileira de Ciências Sociais, 5(14), 73-90.

Lei $n$. 284, de 28 de outubro de 1936. (1936). Reajusta os quadros e os vencimentos do funccionalismo publico civil da União e estabelece diversas providencias. Rio de Janeiro, DF.

Loureiro, M. R. (1997). Os economistas no governo: gestão econômica e democracia. Rio de Janeiro, RJ: Ed. FGV.

Martins, L. (1987). A gênese de uma intelligentsia: os intelectuais e a política no Brasil (1920 a 1940). Revista Brasileira de Ciências Sociais, 2(4), 65-87.

Miceli, S. (1981). Carne e osso da elite política brasileira. In B. Fausto (Org.), História geral da civilização brasileira: o Brasil Republicano sociedade e política (1930-1964) (pp. 574-578). São Paulo, SP: Difel.

Miceli, S. (2001a). Intelectuais e classe dirigente no Brasil (1920-1945). In Autor, Intelectuais à brasileira (pp. 69-291). São Paulo, SP: Companhia das Letras.

Miceli, S. (2001b). Biografia e cooptação (o estado atual das fontes para a história social e política das elites no Brasil). In Autor, Intelectuais à brasileira (pp. 345-356). São Paulo, SP: Companhia das Letras.

Moreira, R. L. (2001). Ildefonso Simões Lopes. In A. A. Abreu (Coord.), Dicionário histórico-biográfico brasileiro: pós-1930 (2a ed., pp. 3270-3272). Rio de Janeiro, RJ: Ed. FGV.

Nunes, E. O. (2003). A gramática política do Brasil: clientelismo e insulamento burocrático (3a ed.). Rio de Janeiro, RJ: Zahar.

Passeron, J.-C. (1990). Biographies, flux, itinéraires, trajectoires. Revue Française de Sociologie, 31(1), 3-22.

Pécaut, D. (1990). Os intelectuais e a política no Brasil: entre o povo e a nação. São Paulo, SP: Ática.
Peneff, J. (1994). Les grandes tendances de l'usage des biographies dans la sociologie française. Politix, 7(27), 25-31.

Petrarca, F. R. (2017). De coronéis a bacharéis: reestruturação das elites e medicina em Sergipe (18401900). Revista Brasileira de História, 37(74), 89-112.

Pudal, B. (1994). Du biographique entre "science" et "fiction". Quelques remarques programmatiques. Politix, 7(27), 5-24.

Saint-Martin, M. (1988). À propos d'une rencontre entre chercheurs. Sciences sociales et politique au Brésil. Actes de la Recherche en Sciences Sociales, 13(71-72), 129-134.

Sapiro, G. (2012). Modelos de intervenção política dos intelectuais: o caso francês. Revista Pós Ciências Sociais, 9(17), 19-50.

Seidl, E. (2008). Elites militares, trajetórias e redefinições político-institucionais (1850-1930). Revista de Sociologia e Politica, 16(30), 199-220.

Seidl, E. (2010). A formação de um exército à brasileira: lutas corporativas e adaptação institucional. História, 29(2), 71-94.

Seidl, E. (2013). Estudar os poderosos: a sociologia do poder e das elites. In E. Seidl, \& I. G. Grill (Orgs.), As ciências sociais e os espaços da política no Brasil (pp. 179-226). Rio de Janeiro, RJ: Ed. FGV.

Seidl, E., \& Grill, I. G. (2013). A política como objeto de estudo nas ciências sociais. In Autores (Orgs.), As ciências sociais e os espaços da politica no Brasil (pp. 7-20). Rio de Janeiro, RJ: Ed. FGV.

Siegel, G. B. (1964). The vicissitudes of governmental reform in Brazil: a study of the Dasp (Ph.D. Thesis). University of Pittsburgh, Pittsburgh, PA.

Sigal, S. (2012). Intelectuais, cultura e política na Argentina. Revista Pós Ciências Sociais, 9(17), 51-66.

Silva, S. B. (Org.). (2006). Luiz Simões Lopes: fragmentos de memória. Rio de Janeiro, RJ: Ed. FGV.

Simões Lopes, L. (1986). Luiz Simões Lopes (Vol. 1, 1979, 1981). Rio de Janeiro, RJ: Centro de Pesquisa e Documentação de História Contemporânea do Brasil.

Simões Lopes, L. (2003). Luiz Simões Lopes (Vol. 2, 1990). Rio de Janeiro, RJ: Centro de Pesquisa e 
RAP | Luiz Simões Lopes entre administração e política: a trajetória de um dirigente

Documentação de História Contemporânea do Brasil.

Simões Lopes, L. (2006a). Amor à natureza. In S. B. Silva (Org.), Luiz Simões Lopes: fragmentos de memória (pp. 45-59). Rio de Janeiro, RJ: Ed. FGV.

Simões Lopes, L. (2006b). O privilégio de ser gaúcho. In S. B. Silva (Org.), Luiz Simões Lopes: fragmentos de memória (pp. 23-43). Rio de Janeiro, RJ: Ed. FGV.

Simões Lopes, L. (2006c). Paixão pela administração. In S. B. Silva (Org.), Luiz Simões Lopes: fragmentos de memória (pp. 85-117). Rio de Janeiro, RJ: Ed. FGV.

Simões Lopes, L. (2006d). Política: tragédia e revolução. In S. B. Silva (Org.), Luiz Simões Lopes: fragmentos de memória (pp. 61-83). Rio de Janeiro, RJ: Ed. FGV.

Simões Lopes, L. (n.d.). Correspondência (sem título). Rio de Janeiro, RJ: Centro de Pesquisa e Documentação de História Contemporânea do Brasil.

Wahrlich, B. M. S. (1983). Reforma administrativa na era de Vargas. Rio de Janeiro, RJ: Ed. FGV.

Wahrlich, B. M. S. (2001). Departamento Administrativo do Serviço Público. In A. A. Abreu (Coord.), Dicionário histórico-biográfico brasileiro: pós-1930 (2a ed., pp. 1827-1830). Rio de Janeiro, RJ: Ed. FGV.

\section{Daniel Ouriques Caminha}

https://orcid.org/0000-0003-2933-9852

Aluno de Doutorado em Administração na Universidade do Estado de Santa Catarina (UDESC); Mestre em Administração pela Universidade Federal do Rio Grande do Sul (UFRGS). E-mail: dan.caminha@gmail.com 